\title{
Concentração foliar de nutrientes e produtividade de tomateiro cultivado sob diferentes substratos e doses de ácidos húmicos
}

\author{
Antonio A de Lima ${ }^{1}$; Marco Antonio R Alvarenga ${ }^{2}$; Leandro Rodrigues ${ }^{2}$; Janice G de Carvalho ${ }^{3}$ \\ ${ }^{1}$ IFE, C. Postal 51, Colorado do Oeste-RO; ${ }^{2}$ UFLA-Depto. Agricultura, C. Postal 3037, 37200-000 Lavras-MG; ${ }^{3}$ UFLA, Depto. Ciências \\ do Solo; anilimaufla@hotmail.com
}

\section{RESUMO}

Este trabalho foi realizado com o objetivo de avaliar o estado nutricional e a produtividade do tomateiro, híbrido Vênus, cultivado em substratos, com aplicação de ácidos húmicos $(\mathrm{AH})$ e fertirrigação. Foram avaliadas quatro doses de $\mathrm{AH}\left(0,20,40\right.$ e $\left.80 \mathrm{~L} \mathrm{ha}^{-1}\right)$ e quatro substratos: S1 (fibra de coco (FC)), S2 (FC + casca de café carbonizada (CC) na proporção $1: 3), \mathrm{S} 3(\mathrm{FC}+\mathrm{CC}$ na proporção $2: 3)$ e S4 (CC). O delineamento experimental foi em blocos casualizados distribuídos em esquema fatorial $4 \times 4$. As mudas foram transplantadas com 35 dias para sacolas plásticas com capacidade de 7,0 L. Os AH foram aplicados quatro vezes em um intervalo de oito dias, sendo a primeira aplicação oito dias após o transplantio. Não houve efeito significativo dos tratamentos nos teores de N, K e $\mathrm{S}$ nas folhas e na produção de frutos não comerciais. No entanto, houve efeito significativo dos substratos nos teores de $\mathrm{P}, \mathrm{Ca}, \mathrm{Mg}$ e sobre a produção de frutos total e comercial. Doses crescentes de $\mathrm{AH}$ induziram redução de forma linear dos teores de B e Cu (em S1); porém, induziram aumento dos teores de Zn. Em doses de 31 a 49 $\mathrm{L} \mathrm{ha}^{-1}$ de $\mathrm{AH}$, ocorreu o máximo teor foliar de $\mathrm{Fe}, \mathrm{Cu}$ e o mínimo de $\mathrm{Mn}$. As maiores produtividades comerciais foram obtidas com a fibra de coco (S1) com média de 5,6 kg planta ${ }^{-1}$, apresentando incremento médio de produtividade de $22,9 \%, 38,7 \%$ e $49,7 \%$ em relação a $S 2$, $\mathrm{S} 3$ e $\mathrm{S} 4$, respectivamente.

Palavras-chave: Lycopersicon esculentum, ácidos húmicos, substratos alternativos, fibra de coco, casca de café carbonizada.

\begin{abstract}
Leaf nutrient content and yield of tomato grown in different substrates and doses of humic acids

We evaluated the nutritional status and yield of tomato hybrid "Vênus", grown on substrates, with application of humic acids (AH) and fertigation. Four doses of AH $\left(0,20,40\right.$ and $80 \mathrm{~L}^{-1}$ ha) and four substrates: $\mathrm{S} 1$ (coconut fiber $(\mathrm{CF})$ ), S2 (FC + carbonized coffee husk (CC) in the ratio 1:3), S3 (CF + CC - in the ratio 2:3) and S4 (CC) were evaluated following the randomized blocks design in factorial $4 \times 4$ scheme with four replications. The 35 -day old seedlings were transplanted into plastic bags of $7 \mathrm{~L}$. The humic acids were applied four times in eight-day intervals, and the first application was carried out eight days after transplanting. There was no significant effect of the treatments on the content of N, K and S in leaves and on nonmarketable fruits yield. However, there was a significant effect of the substrates on the content of $\mathrm{P}, \mathrm{Ca}, \mathrm{Mg}$ and on the total and marketable fruit yield. Increasing doses of AH reduced linearly the content of $\mathrm{B}$ and $\mathrm{Cu}$ (on $\mathrm{S} 1$ ), but increased the content of $\mathrm{Zn}$ in leaves. Humic acid doses of 31 to $49 \mathrm{~L} \mathrm{ha}^{-1}$ provided the highest contents of $\mathrm{Fe}$, $\mathrm{Cu}$, and the lowest content of $\mathrm{Mn}$. The highest marketable yields were obtained using coconut fiber, with an average of $5.6 \mathrm{~kg} / \mathrm{plant}$, showing an average yield increase of $22.9 \%, 38.7 \%$ and $49.7 \%$ in comparison to $\mathrm{S} 2, \mathrm{~S} 3$ and $\mathrm{S} 4$, respectively.
\end{abstract}

Keywords: Lycopersicon esculentum, humic acids, alternative substrates, coconut fiber, carbonized coffee husk.

(Recebido para publicação em 4 de setembro de 2009; aceito em 4 de fevereiro de 2011) (Received on September 4, 2009; accepted on February 4, 2011)

$\mathrm{O}$ cultivo em ambiente protegido permite a produção de hortaliças em qualquer época do ano, mesmo em condições climáticas desfavoráveis, possibilitando o prolongamento do período de colheita, o aumento da produtividade e a melhoria da qualidade do produto (Makishima \& Carrijo, 1998).

$\mathrm{Na}$ escolha do substrato devem ser consideradas suas propriedades físicas e químicas, densidade, boa retenção de água e nutrientes, disponibilização de oxigênio, alta capacidade de troca de cátions, baixa relação $\mathrm{C} / \mathrm{N}$, entre outras; o que proporcionará maior crescimento e desenvolvimento do tomateiro e consequentemente maior produtividade (Martinez, 2002). É importante utilizar substratos de materiais inertes, de longa durabilidade, baixo custo, fácil utilização e disponível nas regiões de cultivo.

Os ácidos húmicos são ácidos orgânicos, solúveis em água, presentes em diferentes fontes orgânicas, tais como lodo de esgoto, composto orgânico, leonardita, turfa e produtos comerciais, e que estimulam a absorção de nutrientes, principalmente de íons catiônicos. Os resultados obtidos são variáveis e dependem, além da espécie testada, das substâncias húmicas utilizadas, concentração, grau de purificação do material e das condições em que foram realizados os experimento (Silva et al., 1999).

As substâncias húmicas aumentam a atividade de $\mathrm{H}^{+}$-ATPases de membranas plasmáticas, estimulam o desenvolvimento de raízes, resultando em maior absorção e transporte de nutrientes (Façanha et al., 2002). No tomateiro, estimulam o crescimento de raízes e da parte aérea, resultando em maior teor de massa seca da planta e dos frutos, além de proporcionar maior produtividade e absorção de $\mathrm{N}, \mathrm{P}, \mathrm{Fe}$ e $\mathrm{Cu}$ (Abdel-Mawgoud et al., 2007; Yildirim, 2007).

Este trabalho foi desenvolvido com o objetivo de avaliar a produtividade e o teor de nutrientes nas folhas do tomateiro, grupo italiano, cultivado em ambiente protegido em diferentes substratos e doses de ácidos húmicos.

\section{MATERIAL E MÉTODOS}


O experimento foi conduzido no setor de Olericultura da UFLA, LavrasMG, de agosto de 2007 a janeiro de 2008. As sementes da cultivar híbrida Vênus, grupo italiano, de crescimento determinado, foram semeadas em bandejas de poliestireno com 128 células e irrigadas diariamente por meio de microaspersão.

As mudas foram transplantadas 35 dias após a semeadura para sacolas plásticas com capacidade de 7,0 L, sendo distribuídas no espaçamento de $1,0 \mathrm{~m}$ x 0,8 m x 0,4 m (entre fileiras duplas, fileiras simples e plantas na mesma fileira, respectivamente), com densidade populacional de 2,78 plantas $\mathrm{m}^{-2}$. A condução do experimento foi em ambiente protegido, modelo capela, com $30 \mathrm{~m}$ de comprimento, $10 \mathrm{~m}$ de largura e $1,80 \mathrm{~m}$ de pé direito, coberto com polietileno de baixa densidade de 150 micras.

O delineamento experimental utilizado foi de blocos casualizados em esquema fatorial $4 \times 4$, compreendendo quatro doses de ácidos húmicos $(0,20$, 40 e $80 \mathrm{~L} \mathrm{ha}^{-1}$ ) e quatro tipos de substratos: $\mathrm{S}_{1}$ (fibra de coco $\left.(\mathrm{FC})\right) ; \mathrm{S}_{2}(\mathrm{FC}$

Tabela 1. Características físico-químicas dos substratos orgânicos (physico-chemical properties of organic substrates). Lavras, UFLA, 2008.

\begin{tabular}{lrrrrr}
\hline Características & \multicolumn{1}{c}{ S1 } & \multicolumn{1}{c}{ S2 } & \multicolumn{1}{c}{ S3 } & S4 & Coda 20 \\
\hline $\mathrm{pH} \mathrm{em} \mathrm{H} \mathrm{O}$ & 5,8 & 7,2 & 7,3 & 7,8 & - \\
$\mathrm{N}-\mathrm{Total}\left(\mathrm{g} \mathrm{kg}^{-1}\right)$ & 9,2 & 8,7 & 9,7 & 8,2 & 4,0 \\
$\mathrm{P}\left(\mathrm{g} \mathrm{kg}^{-1}\right)$ & 2,0 & 2,4 & 2,5 & 2,5 & 33,4 \\
$\mathrm{~K}\left(\mathrm{~g} \mathrm{~kg}^{-1}\right)$ & 8,2 & 17,7 & 22,0 & 30,5 & 37,1 \\
$\mathrm{Ca}\left(\mathrm{g} \mathrm{kg}^{-1}\right)$ & 4,2 & 10,2 & 8,2 & 9,1 & 1,7 \\
$\mathrm{Mg}\left(\mathrm{g} \mathrm{kg}^{-1}\right)$ & 1,5 & 2,8 & 2,5 & 2,3 & 0,3 \\
$\mathrm{~S}\left(\mathrm{~g} \mathrm{~kg}^{-1}\right)$ & 2,3 & 2,5 & 2,7 & 2,4 & 7,5 \\
$\mathrm{~B}\left(\mathrm{mg} \mathrm{kg}^{-1}\right)$ & 29,5 & 19,6 & 21,4 & 21,2 & - \\
$\mathrm{Cu}\left(\mathrm{mg} \mathrm{kg}^{-1}\right)$ & 85,2 & 57,7 & 61,8 & 45,0 & - \\
$\mathrm{Mn}\left(\mathrm{mg} \mathrm{kg}^{-1}\right)$ & 77,8 & 182,0 & 157,1 & 164,2 & 7,1 \\
$\mathrm{Zn}\left(\mathrm{mg} \mathrm{kg}^{-1}\right)$ & 84,2 & 52,9 & 55,0 & 29,7 & 16,2 \\
Fe $\left(\mathrm{mg} \mathrm{kg}^{-1}\right)$ & 716,3 & $1.256,1$ & $1.265,1$ & $1.188,9$ & 102,1 \\
$\mathrm{C} . \mathrm{E} .\left(\mathrm{mS} \mathrm{cm}^{-1}\right)$ & 3,8 & 3,9 & 4,9 & 5,6 & - \\
$\mathrm{C}$ total $\left(\mathrm{dag} \mathrm{kg}^{-1}\right)$ & 40,6 & 40,6 & 36,9 & 41,0 & 9,9 \\
$\mathrm{C} / \mathrm{N}$ & 44,1 & 46,7 & 38,0 & 50,0 & 24,9 \\
Ácido húmico $\left(\mathrm{g} \mathrm{kg}^{-1}\right)$ & 2,0 & 2,5 & 1,4 & 2,5 & 100,0 \\
Ácido fúlvico $\left(\mathrm{g} \mathrm{kg}^{-1}\right)$ & 3,2 & 2,4 & 1,6 & 3,7 & 102,0 \\
\hline
\end{tabular}

S1: fibra de coco (FC); S2: FC + casca de café carbonizada (CC) na proporção 1:3; S3: FC + CC na proporção 2:3; S4: CC; C.E.: Condutividade elétrica; Coda 20: Codahumus 20, Acido húmico (S1: coconut fiber (FC); S2: FC + carbonized coffee husk (CC) in the ratio $1: 3$; $\mathrm{S} 3$ : $\mathrm{FC}+\mathrm{CC}$ in the ratio 2:3; $\mathrm{S} 4$ : CC); C.E.: electrical conductivity; Coda 20: Codahumus 20, humic acid).

+ casca de café carbonizada (CC) na proporção $1: 3$, com base em volume); $\mathrm{S}_{3}(\mathrm{FC}+\mathrm{CC}$ na proporção $2: 3$, com base em volume); e $\mathrm{S}_{4}$ (CC) (Tabela 1). Como fonte de $\mathrm{AH}$ foi utilizado o Codahumus 20, aplicado a cada oito dias, em quatro parcelamentos, a partir do oitavo dia após o transplantio (Tabela 1). As parcelas foram constituídas por nove plantas, sendo as amostras retiradas de cinco plantas centrais em cada parcela com quatro repetições.

Os nutrientes foram fornecidos por meio de fertirrigação diária, de acordo com o estádio de desenvolvimento da cultura, sendo as doses baseadas em recomendação de Castellane \& Araújo (1995). Na fase inicial de crescimento foram aplicados: 12,5 de $\mathrm{N}$; 1,5 de P; 7,0 de $\mathrm{K} ; 4,0$ de $\mathrm{Ca} ; 2,0$ de $\mathrm{Mg} ; 2,0$ de $\mathrm{S}\left(\mathrm{mmol} \mathrm{L}^{-1}\right)$; e, ainda 20 de Fe; 15 de Mn; 5 de Zn; 30 de B; 0,8 de Cu; 0,5 de o $\left(\mu \mathrm{mol} \mathrm{L}{ }^{-1}\right)$. Na fase de crescimento 15 de $\mathrm{Mn} ; 5$ de $\mathrm{Zn} ; 30$ de B; 0,8 de $\mathrm{Cu}$; 0,5 de $\mathrm{Mo}(\mu \mathrm{mol} \mathrm{L}-1)$. 
comercial de frutos, e ainda em relação aos teores foliares de P, Ca e Mg (Tabela 2). No entanto, não foi observado efeito significativo dos ácidos húmicos $(\mathrm{AH})$ com relação à produção de frutos total, comercial, não comercial, bem como, em relação aos teores foliares de macronutrientes. Isso, provavelmente, ocorreu devido à lixiviação dos $\mathrm{AH}$, produzida pela alta frequência de regas, à utilização de solução nutritiva equilibrada ou à capacidade de disponibilização gradual de AH pelos substratos (Tabela 1). A produção total de frutos de tomateiro foi gradualmente reduzida, à medida que se aumentou o teor de casca de café nos substratos.

Na fibra de coco, houve incremento médio de produção de frutos comerciais de $22,9 \%, 38,7 \%$ e $49,7 \%$, em relação a S2, S3 e S4 (Tabela 2). Cabe ressaltar que a estimativa média da produção comercial nos substratos, de 125,9 $\mathrm{t} \mathrm{ha}^{-1}$ foi superior à obtida em cultivo hidropônico NFT, com as cultivares UC-82 e Saladinha, com médias de 85,5 a 101,3 t ha-1 (Genúncio et al., 2006) e com a utilização de fibra de coco e fertirrigação, cvs. TX e Larissa, médias de $104 \mathrm{t} \mathrm{ha}^{-1}$ (Carrijo et al., 2004). A produção comercial média nos diferentes tratamentos foi influenciada pelo tipo de substrato e manejo da irrigação. A casca de café carbonizada apresentou alta capacidade de disponibilização de potássio, 3,7 vezes mais que a fibra de coco, alterando a condutividade elétrica (C.E.) e o pH da solução de cultivo (Tabela 1), influenciando significativamente na redução da produtividade do tomateiro. De acordo com Alvarenga et al. (2004), o limite máximo de salinidade expressa pelo solo para o tomateiro é de $2,5 \mathrm{mS} \mathrm{cm}^{-1}$, ocorrendo diminuição de rendimento de $10 \%$ para cada acréscimo de $1,0 \mathrm{mS}$ $\mathrm{cm}^{-1}$, acima do limite de tolerância.

A produção média de frutos não comerciais não foi influenciada significativamente pelos diferentes substratos (Tabela 2). No entanto, é importante salientar que, apesar disso, as perdas por deficiência de $\mathrm{Ca}$ foram 16,7\% maiores em S2 e em S3 do que em S1(fibra de coco). A produção média estimada de frutos não comerciais, de 4,6 t ha ${ }^{-1}$, constituída principalmente por tomates com deficiência de cálcio, encontrava-se dentro dos valores médios, de 3,8 a 5,8 tha $^{-1}$, observados por Sampaio et al. (1999) para a cv. Santa Clara. Os fatores mais prováveis para a ocorrência de podridão apical podem estar relacionados com alta umidade relativa do ar no período de colheita e diminuição de fluxo transpiratório de água e nutrientes, para parte aérea, influenciando a redistribuição de $\mathrm{Ca}^{+2}$ para frutos. Nesse caso, Paiva et al. (1998) verificaram maior acúmulo de cálcio nos frutos, em condições de baixa umidade relativa (40\%), por aumentar o fluxo transpiratório de água e nutrientes para a parte aérea e, consequentemente, para os frutos.

Houve diferença significativa para os teores de $\mathrm{Ca}$ e $\mathrm{Mg}$ nas folhas nos diferentes substratos, observando-se maiores concentrações desses nutrientes nos substratos com casca de café carbonizada (Tabela 2). No entanto, não houve influência, do ponto de vista nutricional, capaz de elevar a produtividade do tomateiro. A ordem decrescente de concentração de nutrientes nas folhas do tomateiro nos diferentes tratamentos foi: N, K, Ca, Mg, S e P. Esse resultado foi diferente do observado por Fernandes et al. (2002) com o híbrido Carmen, cultivado em solução nutritiva, apresentando valores de $\mathrm{K}>\mathrm{Ca}>\mathrm{N}>\mathrm{S}>\mathrm{P}>\mathrm{Mg}$. As diferenças entre os teores foliares de nutrientes, referidos por diversos autores, dependem da época de plantio, da idade da planta ou órgão amostrado, da cultivar, da interação entre nutrientes e das condições climáticas (Carvalho et al., 2004).

O teor foliar de nitrogênio não foi influenciado pelos tratamentos (Tabela 2), porém, ficou dentro dos níveis de concentração considerados adequados,

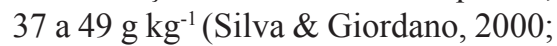
Fontes et al., 2004). Segundo Fayad et al. (2002), a taxa diária de absorção de $\mathrm{N}$ pelo tomateiro é crescente até aos 46 dias, para depois decrescer, devido à sua exportação para frutos, cuja taxa é de $55 \%$. Provavelmente, devido ao fato de a amostragem foliar ter sido realizada por ocasião da formação do segundo cacho de frutos, a redistribuição tenha influenciado a concentração de $\mathrm{N}$ foliar.

O teor de fósforo nas folhas foi influenciado pelos substratos, sendo significativamente menor apenas no substrato com fibra de coco (Tabela 2). No entanto, o menor teor de P, de 6,0 $\mathrm{g} \mathrm{kg}^{-1}$, permaneceu dentro dos níveis considerados adequados para o tomateiro, de 2,5 a 8,0 $\mathrm{g} \mathrm{kg}^{-1}$ (Malavolta et al., 1997; Silva \& Giordano, 2000). Porém,

Tabela 2. Teores médios de N, P, K, Ca, Mg e S nas folhas e produção total (PT), comercial (PC) e não comercial (PNC) de frutos de tomateiro cultivado em diferentes substratos orgânicos (average content of N, P, K, Ca, Mg and S in leaves and production total (PT), marketable yield (PC) and non-marketable yield (PNC) of tomato fruits grown on different organic substrates). Lavras, UFLA, 2008.

\begin{tabular}{|c|c|c|c|c|c|c|c|c|c|}
\hline \multirow{2}{*}{ Substratos } & PT & PC & PNC & $\mathbf{N}$ & $\mathbf{P}$ & $\mathbf{K}$ & $\mathrm{Ca}$ & Mg & $\mathbf{S}$ \\
\hline & \multicolumn{3}{|c|}{$\left(\right.$ kg planta $\left.^{-1}\right)$} & \multicolumn{6}{|c|}{$\left(\mathrm{g} \mathrm{kg}^{-1}\right)$} \\
\hline S1 & $5,74 \mathrm{a}$ & $5,59 \mathrm{a}$ & $0,14 \mathrm{a}$ & $39,0 \mathrm{a}$ & $6,0 \mathrm{~b}$ & $33,0 \mathrm{a}$ & $34,0 \mathrm{a}$ & $7,0 \mathrm{~b}$ & $7,8 \mathrm{a}$ \\
\hline $\mathrm{S} 2$ & $4,49 \mathrm{~b}$ & $4,31 \mathrm{~b}$ & $0,15 \mathrm{a}$ & $40,0 \mathrm{a}$ & $6,7 \mathrm{a}$ & $34,0 \mathrm{a}$ & $30,0 \mathrm{~b}$ & $7,5 \mathrm{a}$ & $7,1 \mathrm{a}$ \\
\hline $\mathrm{S} 3$ & $4,11 b c$ & $3,92 \mathrm{bc}$ & $0,18 \mathrm{a}$ & $37,0 \mathrm{a}$ & $6,9 \mathrm{a}$ & $33,0 \mathrm{a}$ & $30,0 \mathrm{~b}$ & $7,6 \mathrm{a}$ & $7,2 \mathrm{a}$ \\
\hline S4 & $3,78 \mathrm{c}$ & $3,64 \mathrm{c}$ & $0,18 \mathrm{a}$ & $39,0 \mathrm{a}$ & $6,6 \mathrm{ab}$ & $31,0 \mathrm{a}$ & $31,0 \mathrm{~b}$ & $7,6 \mathrm{a}$ & $6,3 \mathrm{a}$ \\
\hline Média & 4,53 & 4,37 & 0,16 & 39,0 & 6,6 & 33,0 & 31,0 & 7,4 & 7,1 \\
\hline CV (\%) & 11,42 & 12,20 & 35,02 & 8,33 & 6,63 & 7,36 & 6,10 & 4,12 & 9,97 \\
\hline
\end{tabular}

Nas colunas, médias seguidas pela mesma letra não diferem entre si pelo teste de Tukey, a 5\% de probabilidade (means followed by the same letter in the column do not differ according to Tukey's test at the 5\% level of probability); S1: fibra de coco (FC); S2: FC + casca de café carbonizada (CC) na proporção 1:3; S3: FC + CC na proporção 2:3; S4: CC (S1: coconut fiber (FC); S2: FC + carbonized coffee husk (CC) in the ratio $1: 3 ; \mathrm{S} 3: \mathrm{FC}+\mathrm{CC}$ in the ratio $2: 3 ; \mathrm{S} 4: \mathrm{CC})$. 


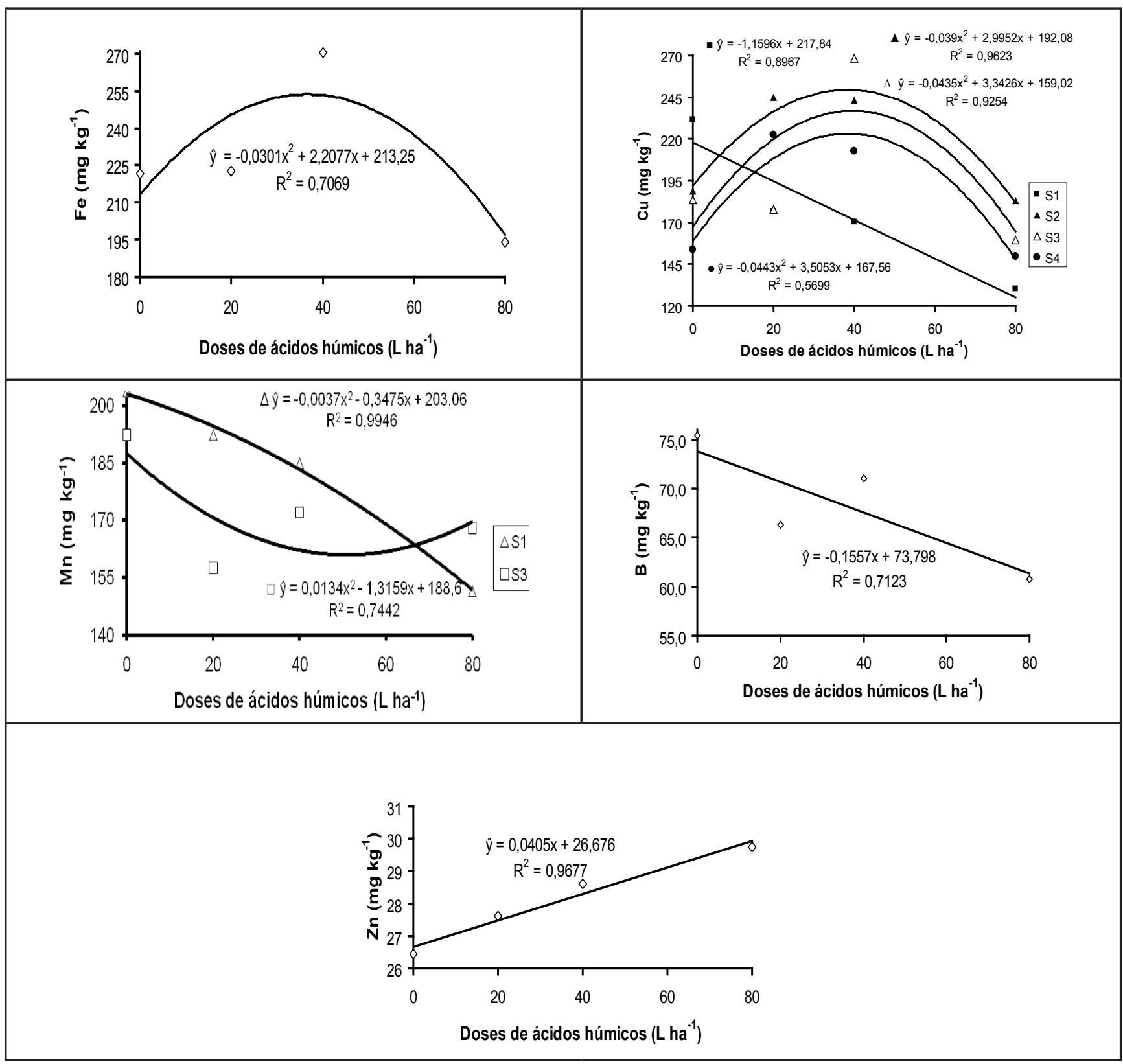

Figura 1. Teores médios de $\mathrm{Fe}, \mathrm{Cu}, \mathrm{Mn}, \mathrm{B}$ e $\mathrm{Zn}$ em folhas de tomateiro ( $\mathrm{p}<0,05)$, em função das doses de ácidos húmicos aplicados em diferentes substratos orgânicos; S1: fibra de coco (FC); S2: FC + casca de café carbonizada (CC) na proporção 1:3; S3: FC + CC na proporção 2:3; S4: CC (average contents of $\mathrm{Fe}, \mathrm{Cu}, \mathrm{Mn}, \mathrm{B}$ and $\mathrm{Zn}$ in tomato leaves ( $\mathrm{p}<0,05)$, depending on the doses of humic acids applied and different organic substrates; S1: coconut fiber (FC); S2: FC + carbonized coffee husk (CC) in the ratio 1:3; S3: FC + CC in the ratio 2:3; S4: CC). Lavras, UFLA, 2008.

inferior aos referidos por Fernandes et al. (2002) em cultivo em vaso, 13 $\mathrm{g} \mathrm{kg}^{-1}$. Provavelmente, as diferenças observadas na concentração de P nos substratos $\mathrm{S} 2$ e S3, estejam relacionadas à maior capacidade de disponibilização de P pela casca de café carbonizada, ou à sua maior capacidade de retenção de ânions, quando comparada com a fibra de coco (Tabela 1).

Não houve efeito significativo dos tratamentos sobre o teor de potássio nas folhas (Tabela 2). No entanto, o menor teor de $\mathrm{K}$ em relação ao substrato com casca de café (S4), de $31 \mathrm{~g} \mathrm{~kg}^{-1}$, ficou dentro do padrão considerado adequado, de 30 a $50 \mathrm{~g} \mathrm{~kg}^{-1}$ (Silva \& Giordano, 2000; Silva et al., 2001). Mesmo assim, a concentração de $\mathrm{K}$ nas folhas foi menor que os 47 a $54 \mathrm{~g} \mathrm{~kg}^{-1}$ citadas por Fernandes et al. (2002) e Fontes et al. (2004), cujos resultados diferiram de acordo com a fonte de nutrientes utilizados e com o ambiente de cultivo, em campo ou ambiente protegido. Porém, estão dentro dos teores de 28 a $33 \mathrm{~g} \mathrm{~kg}^{-1}$, obtidos por Silva et al. (2001) e considerados adequados para o tomateiro.

Houve efeito significativo dos substratos no teor de Ca nas folhas do tomateiro (Tabela 2). No entanto, o menor teor de $\mathrm{Ca}\left(30 \mathrm{~g} \mathrm{~kg}^{-1}\right.$ nos substratos $\mathrm{S} 3 \mathrm{e}$ S2) está dentro dos níveis considerados adequados para o tomateiro, de 13 a 38 (Silva \& Giordano, 2000; Fontes et al., 2004). A fibra de coco no substrato S1 
proporcionou maior absorção de $\mathrm{Ca}$ do que os demais com mistura de casca de café carbonizada. Esse fato pode ser explicado devido à fibra de coco apresentar maior capacidade de retenção e disponibilização de água, facilitando o transporte unidirecional de $\mathrm{Ca}$ pelo xilema, via corrente transpiratória, das raízes para a parte aérea (Faquin, 2005). Por outro lado, com a adição da casca de café carbonizada, ocorreu aumento da CE (Tabela 1) e da inibição competitiva do Ca com $\mathrm{K}$ ou $\mathrm{Mg}$ pelo mesmo sítio do carregador na membrana plasmática, diminuindo o teor desse nutriente nas folhas.

Houve efeito estatisticamente significativo dos substratos no teor de magnésio nas folhas, sendo o menor valor observado no substrato contendo fibra de coco (Tabela 2). No entanto, a menor concentração foliar de $\mathrm{Mg}$, de $7,0 \mathrm{~g} \mathrm{~kg}^{-1}$, está dentro dos níveis considerados adequados para o tomateiro, de 4,0 a $6,0 \mathrm{~g} \mathrm{~kg}^{-1}$ por (Silva \& Giordano, 2000; Fontes et al., 2004). Foi observado ainda, que os substratos contendo casca de café carbonizada apresentaram maior capacidade de disponibilização de $\mathrm{Mg}$ do que a fibra de coco, bem como maior CTC, contribuindo para aumentar o teor foliar (Tabela 2). Portanto, podem influenciar o teor de $\mathrm{Mg}$, o tipo de substrato, o sistema de cultivo, o ambiente e, ainda, segundo Carvalho et al. (2004), a disponibilidade elevada de $\mathrm{Ca}$ e $\mathrm{K}$ na solução de cultivo.

Não houve efeito significativo dos tratamentos com relação ao teor de enxofre nas folhas do tomateiro (Tabela $2)$. No entanto, o menor teor de $\mathrm{S}$, de $6,3 \mathrm{~g} \mathrm{~kg}^{-1}$, está dentro do padrão de concentração considerado adequado para o tomateiro, de 4,0 a 12,0 $\mathrm{g} \mathrm{kg}^{-1}$ (Silva \& Giordano, 2000). É importante ressaltar que os teores foliares de $\mathrm{S}$, em cultivo em diferentes substratos e em ambiente protegido, foram maiores que em sistema de cultivo convencional, variando de 13,0 a 9,0 $\mathrm{g} \mathrm{kg}^{-1}$ (Fontes et al., 2004).

Observou-se que na casca de café carbonizada, quando utilizada sozinha, houve redução de 19,2\% de S nas folhas, quando comparada com a fibra de coco. Essa redução ocorreu devido, provavelmente, à competição entre o sulfato $\left(\mathrm{SO}_{4}{ }^{2-}\right)$ (forma absorvida pela planta) com grupos funcionais do íon carboxilato $\left(\mathrm{COO}^{-}\right)$, e ou hidroxilas $\left(\mathrm{OH}^{-}\right)$ dos grupos fenólicos da casca de café, favorecendo a sua lixiviação, já que os substratos utilizados apresentaram baixa capacidade de retenção de ânions.

Os ácidos húmicos $(\mathrm{AH})$ apresentaram efeito significativo sobre os teores foliares de micronutrientes. É importante salientar o efeito significativo das interações AH e substratos orgânicos, apenas com relação aos teores de $\mathrm{Cu}$ e Mn (Figura 1). Os teores foliares de Fe foram maiores que $\mathrm{Cu}$, seguidos do $\mathrm{Mn}$, $\mathrm{B}$ e $\mathrm{Zn}$, com médias nos diferentes tratamentos, de 221,5; 193,5; 170,1; 68,7; $28,1 \mathrm{mg} \mathrm{kg}^{-1}$, respectivamente. Em solução nutritiva, Fernandes et al. (2002) obtiveram, com o híbrido Carmen, concentrações foliares, também diferentes das obtidas neste trabalho, com médias de: 209 de Fe; 96 de Zn; 10 de $\mathrm{Cu} ; 665$ de Mn; e 209 de B, em mg kg-1. Essas diferenças nas concentrações de nutrientes dependem da época de plantio, da idade da planta ou órgão amostrado, da cultivar, da interação entre nutrientes, das condições climáticas (Carvalho et al., 2004) e da concentração de nutrientes da solução nutritiva.

Houve efeito crescente dos ácidos húmicos na concentração foliar de ferro (Figura 1), atingindo valor máximo de 253,7 $\mathrm{mg} \mathrm{kg}^{-1}$ na dose de 36,7 $\mathrm{L} \mathrm{ha}^{-1}$. Esse aumento pode ser atribuído à maior solubilidade do Fe por complexação com as substâncias húmicas, ou ainda, à redução do $\mathrm{Fe}^{3+}$ a $\mathrm{Fe}^{2+}$ pelos ácidos húmicos, resultando em maior disponibilidade para as plantas (Adani et al., 1998).

Em doses acima de 36,7 $\mathrm{L} \mathrm{ha}^{-1}$, houve redução na disponibilização de $\mathrm{Fe}$ para a forma reduzida $\mathrm{Fe}(\mathrm{OH})_{3}$, produzida, provavelmente, pela liberação de hidroxilas de grupos fenólicos das substâncias húmicas. No entanto, os teores de Fe nas folhas do tomateiro, de 197,2 a $253,7 \mathrm{mg} \mathrm{kg}^{-1}$, estão dentro do padrão considerado adequado para o tomateiro, de 100 a $300 \mathrm{mg} \mathrm{kg}^{-1}$ (Malavolta et al., 1997; Fernandes et al., 2002).

Houve efeito significativo da interação entre os ácidos húmicos e substratos na concentração foliar de cobre (Figura 1). Houve decréscimo de $23,2 \mathrm{mg} \mathrm{kg}^{-1}$ de $\mathrm{Cu}$, para cada $20 \mathrm{~L}$ do produto apli- cado aos substratos. O efeito do teor de $\mathrm{Cu}$, apresentado pela fibra de coco, difere dos demais substratos onde foi utilizada a casca de café carbonizada. Ao contrário da fibra de coco, a aplicação de doses crescente de ácidos húmicos induziu aumento do teor foliar de $\mathrm{Cu}$, cujos resultados foram representados por curvas de regressão quadráticas, para os substratos com casca de café carbonizada S2, S3 e S4, apresentando nas doses de 38,4 a 39,5 L, as máximas concentrações de $\mathrm{Cu}$, de 249,6; 236,9 e 223,5 $\mathrm{mg} \mathrm{kg}^{-1}$, respectivamente.

Os resultados indicam que a fibra de coco apresenta menor CTC, quando comparada com a casca de café carbonizada. Portanto, é provável que, com o aumento das doses de ácidos húmicos, tenha ocorrido complexação do $\mathrm{Cu}$ com substâncias húmicas, formando um complexo mais estável, reduzindo a sua disponibilização para as plantas ou facilitando perdas por lixiviação, devido à baixa CTC da fibra de coco, quando comparado com a casca da café carbonizada (Tabela 1). Por isso, Correia et al. (2003) recomendam a utilização da fibra de coco misturada a outros materiais, para aumentar a sua eficiência como substrato.

Nos substratos contendo casca de café carbonizada o teor foliar de $\mathrm{Cu}$ cresceu até a dose de aproximadamente 38,4 $\mathrm{L} \mathrm{ha}^{-1}$ de ácidos húmicos, provavelmente, devido à maior CTC e maior concentração do nutriente na solução. Esse resultado pode ser explicado, também, pela ativação $\mathrm{H}^{+}$-ATPases de membranas por substâncias húmicas, especialmente ácidos fúlvicos ou por aumento da permeabilidade da membrana plasmática, implicando em maior absorção de íons, como $\mathrm{Fe}^{2+}$ e $\mathrm{Cu}^{2}$ (Adani et al., 1998; Nardi et al., 1991). No entanto, observou-se que o menor teor foliar de $\mathrm{Cu}$ na dose máxima de $80 \mathrm{~L} \mathrm{ha}^{-1}$ de ácidos húmicos, no caso da fibra de coco, de $125,1 \mathrm{mg} \mathrm{kg}^{-1}$, está acima do padrão considerado adequado para o tomateiro, de 5 a $15 \mathrm{mg} \mathrm{kg}^{-1}$ (Malavolta et al., 1997; Silva \& Giordano, 2000). Altas concentrações de $\mathrm{Cu}$ estão relacionadas também, à aplicação foliar de fungicidas cúpricos para controle de doenças da parte aérea do tomateiro.

Houve efeito da interação entre os 
ácidos húmicos e substratos na concentração foliar de manganês (Figura 1). Na fibra de coco e no substrato $\mathrm{S} 3$, ocorreram teores mínimos de 125,6 mg $\mathrm{kg}^{-1}$ e $151,6 \mathrm{mg} \mathrm{kg}^{-1}$ de Mn respectivamente, nas doses de 47,0 e $80 \mathrm{~L} \mathrm{ha}^{-1}$. A casca de café carbonizada aumenta o pH e a C.E. da solução, diminuindo, consequentemente, a disponibilização de íons catiônicos. Normalmente, a solubilidade e absorção dos micronutrientes catiônicos diminuem com o aumento do pH da solução (Faquin, 2005). Esse efeito nos substratos S1 e S3 foram revertidos em doses de ácidos húmicos superiores a 47,0 $\mathrm{L} \mathrm{ha}^{-1}$, por provável complexação do Mn com ligantes orgânicos (ácidos húmicos e fúlvicos), que podem influenciar na absorção do elemento pelas raízes.

É importante ressaltar que os teores foliares de Mn nos diferentes tratamentos, de 156,3 a $203,1 \mathrm{mg} \mathrm{kg}^{-1}$, estão dentro do padrão considerado adequado para o tomateiro, de 50 a $250 \mathrm{mg} \mathrm{kg}^{-1}$ (Malavolta et al., 1997). Vários fatores interferem na concentração de Mn, dentre eles o tipo de híbrido, ambiente de cultivo, substratos, solução de cultivo ou pulverizações para controle de fitopatógenos da parte aérea. Teores considerados elevados foram observados em cultivo protegido, média de 313,2 mg $\mathrm{kg}^{-1}$ (Rodrigues et al., 2002), geralmente atribuídos ao controle com fungicidas à base de Mn.

Houve efeito significativo dos ácidos húmicos no teor de $\mathrm{B}$ nas folhas do tomateiro (Figura 1), com decréscimo de $3,1 \mathrm{mg} \mathrm{kg}^{-1}$ para cada $20 \mathrm{~L}$ do produto aplicado aos substratos. No entanto, o menor teor foliar de $\mathrm{B}$ na dose máxima de $80 \mathrm{~L} \mathrm{ha}^{-1}$ de ácidos húmicos, de 61,3 $\mathrm{mg} \mathrm{kg}^{-1}$, está dentro do padrão considerado adequado para o tomateiro, de 30 a $100 \mathrm{mg} \mathrm{kg}^{-1}$ (Malavolta et al., 1997; Silva \& Giordano, 2000). A redução do teor de B nas folhas com doses crescentes de ácidos húmicos ocorreu devido, provavelmente à formação de complexos mais solúveis do B com substâncias húmicas presente nos ácidos húmicos, cuja lixiviação pode ter sido facilitada, devido à baixa capacidade de retenção de ânions por parte dos substratos.

Houve aumento da concentração de $\mathrm{Zn}$, de $0,81 \mathrm{mg} \mathrm{kg}^{-1}$ para cada $20 \mathrm{~L}$ aplicados aos substratos (Figura 1). No entanto, observou-se que os teores de $\mathrm{Zn}$, de 26,7 a 29,9 mg kg-1, estão abaixo do padrão considerado adequado para o tomateiro, de 60 a $70 \mathrm{mg} \mathrm{kg}^{-1}$ (Silva \& Giordano, 2000); porém, próximos aos referidos por Fontes et al. (2004), de 26 a $29 \mathrm{mg} \mathrm{kg}^{-1}$. A baixa absorção de $\mathrm{Zn}$ pode ser atribuída à provável interação competitiva com o Fe, ao nível da membrana celular pelo sítio ativo do carregador de íons. $\mathrm{O}$ efeito dos ácidos húmicos no aumento do teor de $\mathrm{Zn}$ pode ser atribuído à formação de complexos solúveis, aumentando a sua disponibilização para a planta.

Os tratamentos apresentaram efeito significativo sobre os teores foliares de macronutrientes, exceto $\mathrm{N}$ e $\mathrm{K}$; no entanto, mantendo-os dentro dos níveis considerados adequados para o tomateiro. A fibra de coco apresentou resultados significativamente superiores aos demais substratos, com relação à produção de frutos total e comercial.

Os teores máximos de $\mathrm{Cu}, \mathrm{Fe}$ e $\mathrm{Mn}$ nas folhas ocorreram com a aplicação de doses médias de ácidos húmicos, de 36 a $49 \mathrm{~L} \mathrm{ha}^{-1}$. No entanto, os teores de B e de $\mathrm{Cu}$ no substrato contendo fibra de coco, diminuíram de forma linear com as doses crescentes de ácidos húmicos, enquanto que a concentração de Zn apresentou uma resposta linear crescente.

\section{REFERÊNCIAS}

ABDEL-MAWGOUD AMR; EL-GREADLY NHM; HELMY YI; SINGER SM. 2007. Responses of tomato plants to different rates of humic-based fertilizer and NPK fertilization. Journal of Applied Sciences Research 3: 169-174.

ADANI F; GENEVINI P; ZACCHEO P; ZOCCH G. 1998. The effect of commercial humic acid on tomato plant growth and mineral nutrition. Journal of Plant Nutrition 21: 561-575.

ALVARENGA MAR; LIMA LA; FAQUIN V. 2004. Fertirrigação. In: ALVARENGA MAR (ed). Tomate: produção em campo, em casade-vegetação e em hidroponia. Lavras: Editora UFLA. p. 123-158.

BREMNER JM. 1965. Total nitrogen. In: BLACK CA. (ed). Methods of soil analysis. Madison: American Society of Agronomy, part 2, p. 1149-1178.

CARRIJO OA; VIDAL MC; REIS NVB; SOUZA RB; MAKISHIMAN. 2004. Produtividade do tomateiro em diferentes substratos e modelos de casas de vegetação. Horticultura Brasileira 22: 05-09.

CARVALHO JG; BASTOS ARR; ALVARENGA
MAR. 2004. Fertirrigação. In: ALVARENGA MAR (ed). Tomate: produção em campo, em casa-de-vegetação e em hidroponia. Lavras: Editora UFLA. p. 63-120.

CASTELLANE PD; ARAÚJO JAC. 1995. Cultivo sem solo: hidroponia. Jaboticabal: FUNEP. 43p.

CORREIA D; ROSA MF; NOROES ERV. 2003. Uso do pó da casca de coco na formulação de substratos para formação de mudas enxertadas de cajueiro anão precoce. Revista Brasileira de Fruticultura 25: 557-558.

FACCANHAAR; FAÇANHAALO; OLIVARESFL; GURIDIFGA; VELLOSOACX; RUMJANEK VMR; BRASIL F; SCHRIPSEMA J; BRAZFILHO R; OLIVEIRA MA; CANELLAS LPC. 2002. Bioatividade de ácidos húmicos: efeitos sobre o desenvolvimento radicular e sobre a bomba de prótons da membrana plasmática. Pesquisa Agropecuária Brasileira 37: 1301-1310.

FAQUIN V. 2005. Nutrição mineral de plantas. Lavras: UFLA/FAEPE. 183 p.: il.

FAYAD JA; FONTES PCR; CARDOSO AA; FINGER FL; FERREIRAFA. 2002. Absorção de nutrientes pelo tomateiro cultivado sob condições de campo e de ambiente protegido. Horticultura Brasileira 20: 90-94.

FERNANDES AA; MARTINEZ HEP; FONTES PCR. 2002. Produtividade, qualidade dos frutos e estado nutricional do tomateiro tipo longa vida conduzido com um cacho, em cultivo hidropônico, em função das fontes de nutrientes. Horticultura Brasileira 20: 564-570

FONTES PCR; LOURES JL; GALVÃO JC; CARDOSO AA; MANTOVANI EC. 2004. Produção e qualidade do tomate produzido em substrato, no campo e em ambiente protegido. Horticultura Brasileira 22: 614-619.

GENÚNCIO GC; MAJEROWICZ N; ZONTA E; SANTOS AM; GRACIA D; AHMED CRM; SILVA MG. 2006. Crescimento e produtividade do tomateiro em cultivo hidropônico NFT em função da concentração iônica da solução nutritiva. Horticultura Brasileira 24: 175-179.

MAKISHIMA NO; CARRIJO OA. 1998. Cultivo protegido do tomateiro. Brasília: EMBRAPACNPH. 20p. Embrapa Hortaliças. Circular Técnica, 13.

MALAVOLTA E; VITTI CG; OLIVEIRA SA. 1997. Avaliação do estado nutricional das plantas: princípios e aplicações. Piracicaba: Associação Brasileira para Pesquisa da Potassa e Fosfato. 319p.

MARTINEZ PF. 2002. Manejo de substratos para horticultura. In: ENCONTRO NACIONAL DE SUBSTRATOS PARA PLANTAS, 3 , 2002, Campinas: Caracterização, manejo e qualidade de substratos para produção de plantas. Campinas: IAC, p. 53-76.

NARDI S; CONCHERI G; DELL'AGNOLA G; SCRIMIN P. 1991. Nitrate uptake and ATPase activity in oat seedlings in the presence of two humic fractions. Soil Biology \& Biochemistry 23: 833-836.

PAIVA EAS; MARTINEZ HEP; CASALI VWD; PADILHA L. 1998. Occurrence of blossom end rot in tomato as a function of calcium 
dose in the nutrient solution and air relative humidity. Journal of Plant Nutrition 21: 2663-2670.

RODRIGUES DS; PONTES AL; MINAMI K;

DIAS CTS. 2002. Quantidade absorvida e concentrações de micronutrientes em tomateiro sob cultivo protegido. Scientia Agrícola 59: 137-145.

SAMPAIO RA; FONTES PCR; SEDIYAMA CS. 1999. Resposta do tomateiro à fertirrigação potássica e cobertura plástica do solo. Pesquisa Agropecuária Brasileira 34: 21-30.
SILVA JBC; GIORDANO LB. 2000. Tomate para processamento industrial. Brasília: Embrapa Comunicação para Transferência de Tecnologia - Embrapa Hortaliças. 168 p.

SILVA RM; JABLONSKI A; SIEWERDT L; SILVEIRA JÚNIOR P. 1999. Crescimento da parte aérea e do sistema radicular do milho cultivado em solução nutritiva adicionada de substâncias húmicas. Revista Brasileira de Agrociência 5: 101-110.

SILVA EC; MIRANDA JRP; ALVARENGA MAR. 2001. Concentração de nutrientes e produção do tomateiro podado e adensado em função do uso de fósforo, de gesso e de fontes de nitrogênio. Horticultura Brasileira 19: 64-69.

WOLF B. 1974. Improvements in azomethine-H method for determination of boron. Communications in Soil Science and Plant Analysis 5: 39-44.

YILDIRIM E. 2007. Foliar and soil fertilization of humic acid affect productivity and quality of tomato. Acta Agriculturae Scandinavica, Section B - Plant Soil Science 57: 182-186. 